\title{
Unusual Presentation of Axillary Artery Injury
}

\author{
Sohail Quazi, Salim Al Lahham*, Ruba Sada, Rehan Zahid, Mutaz Abuelgasim, Shyias Mohammedali, Saif Badran \\ and Talal al hetmi
}

MCh plastic surgeon, Hamad medical corporation, Qatar

*Corresponding author: Salim Al Lahham, plastic surgeon, hamad medical corporation, Doha, Qatar

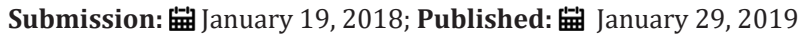

\begin{abstract}
Intra-arterial drug injection is a rare emergency but can occur accidentally by IV drug abusers or iatrogenically in some patients [1]. The accidental injections of some drugs can lead to acute ischemia of the affected limb and digital gangrene [2]. Unintentional intra-arterial injection of drugs either iatrogenic or self-administered, is a source of significant morbidity. Delivery of certain drugs via arterial access can lead to clinically important sequelae, including paresthesias, severe pain, motor dysfunction, compartment syndrome, gangrene, and limb loss [3]. This problem is becoming more common in IV drug addicts.

Drug addicted patients tend to have fibrotic thrombosed peripheral veins due to repetitive injections of highly irritating drugs [4]. We have seen many drug addicted patients with compromised superficial peripheral venous system in both upper and lower limbs in which obtaining a peripheral line is too challenging and hence can lead to accidental intraarterial injection of drugs. We report a case of ruptured axillary artery secondary due to selfinflicted injury by IV tramadol injection in a young tramadol addicted male which was managed successfully by exploration and repair with vein graft.
\end{abstract}

\section{Case Discussion}

A 36 years old male tramadol addicted patient presented with swelling and pain in his right axilla. After thorough questioning the patient admitted that the swelling started two days after his selfadministered injection of tramadol, and it was causing severe pain and discomfort. He also accepted that he was addicted to tramadol and had been taking injection in a similar way since along time. He came to the emergency room after 2 days as he was scared to disclose his drug addiction. On examination the affected upper limb was warm but weaker pulse compared to non-affected side. There was delayed capillary refill and SPO2 saturation was around $82 \%$. He had multiple scars of repeated injection on his both upper and lower limbs.

The axilla on examination had a non-pulsating haematoma of size $6 \times 4 \mathrm{cms}$ which was painful and tender with no other signs of injury. Neurological examination of the affected limb was normal except there was a partial median nerve paralysis with loss of sensation and movements in right index and middle finger. Ultrasound studies reported as Haematoma surrounding the axillary artery with absent flow across the distal segment of axillary artery.

MRI angiography suggested a $6 x 4 \mathrm{cms}$ haematoma surrounding the axillary artery and compressing the median nerve with cut-off at the level of $3^{\text {rd }}$ part of axillary artery with distal runoff suggesting collateral circulation. The patient underwent exploration of the axilla immediately after admission, which showed a hematoma surrounding thrombosed axillary artery with a $4 \mathrm{~cm}$ laceration in the anterior wall of the axillary artery with profuse gush of blood from the proximal axillary artery. Careful dissection was done, proximal control of axillary artery was achieved to control the blood loss. The surrounding tissue near the axillary artery showed dense fibrosis and necrosis of superficial fibres of median nerve.

The thrombosed segment was resected and lesser saphenous vein graft of length $10 \mathrm{cms}$ was used to reconstruct the artery primarily since both great saphenous veins were thrombosed at the leg level due to repeated injections. Neurolysis of the median nerve was done and the necrotic fibres removed. Postoperative there was good flow across the graft and good vascularity was achieved. But 12hours after surgery the upper limb became cold and pulseless so re-exolploration was done which showed a thrombosed vein graft. The graft was resected and a new proximal great saphenous vein graft from the femoral triangle was used to reconstruct the artery. Primary closure of the wound was achieved in both the cases without the need for distal fasciotomy.

He received enoxaparin and antibiotics postoperatively. 1 week postoperatively there was mild infection at the surgical site which was managed conservatively. The patient postoperative period after discharge was uneventful and he recovered completely with recovery of median nerve over a 3 months period (Figures 1-3). 


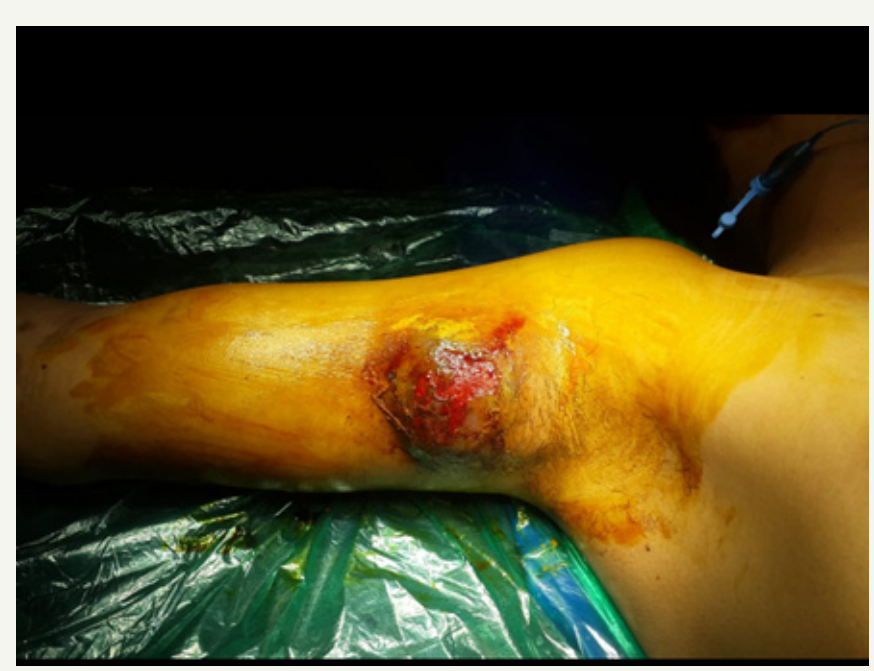

Figure 1: Preoperative swelling of right axilla showing Haematoma in the axilla.

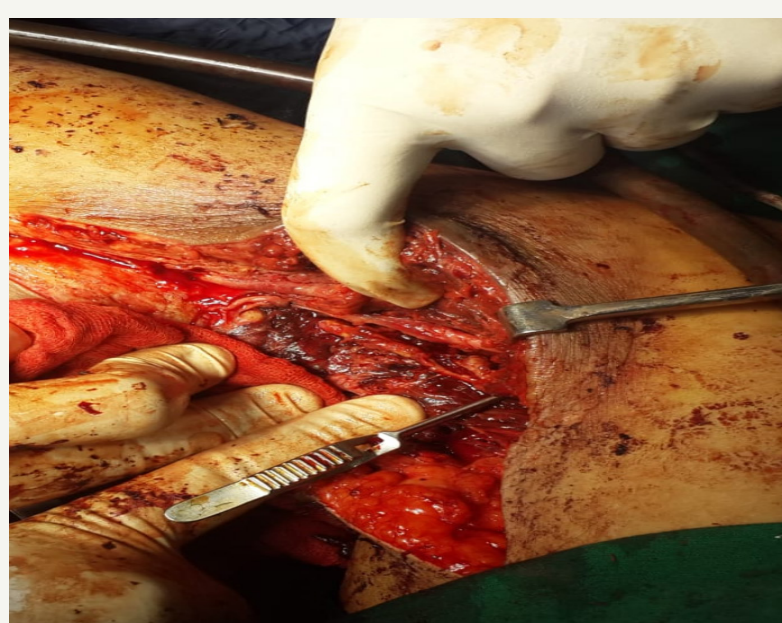

Figure 2: Shows Intraoperative image after exploration and proximal control of axillary artery showing the ruptured segment of the axillary artery with surrounding fibrosis around the artery and necrosis of few fibres of median nerve.

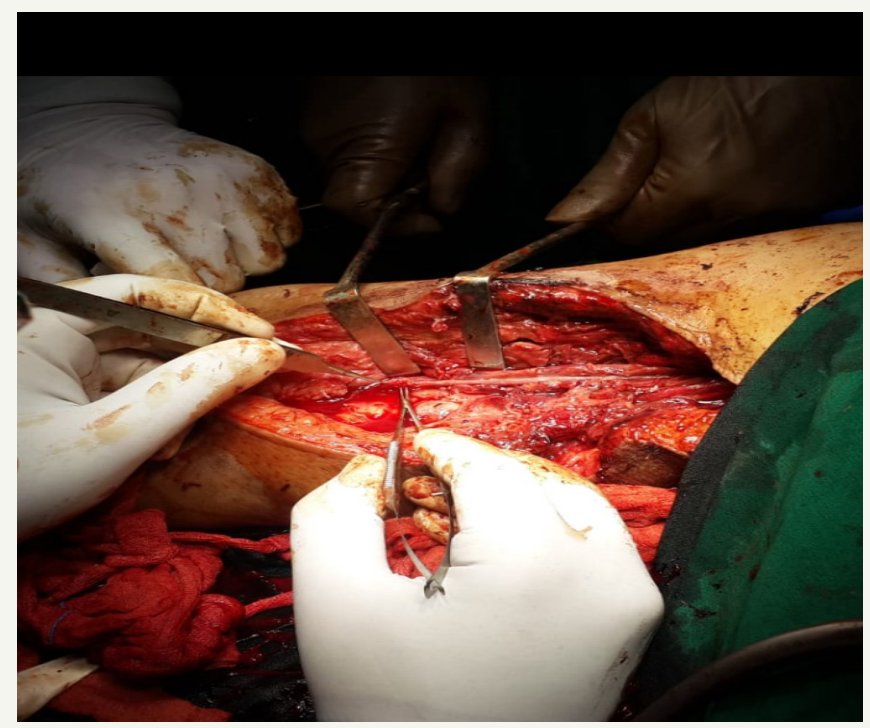

Figure 3: shows greater saphenous vein graft with end to end anastomosis of the vessel and debridement of soft tissue. 


\section{Discussion}

Injection of drug into an artery is a rare event. It may be accidental or associated with drug abuse. The brachial artery is the most common site of accidental injection and intraarterial injection of axillary artery is found to be less common. This has been attributed to easy accessibility of brachial artery and high bifurcation of the artery above the cubital fossa.

Intra-arterial drug injection may cause vessel injury by one of several mechanisms [5].

a) The vessel may be obstructed by inert particles or drug crystals.

b) Vasospasm, hemolysis, platelet aggregation and

c) Venous thrombosis are the other contributory factors.

All this leads to acute thrombosis of the artery. Compromised blood supply to the digits and distal limb due to this thrombosis may lead to gangrene [6].

\section{Conclusion}

A major artery injury can present initially with vague symptoms and signs, but clinical judgement is very critical to make an early intervention to save the affected limb from irreversible complications [7]. An aggressive management strategy is required to prevent gangrene of digit or limb loss. Prompt recognition and early treatment is necessary to prevent amputation and permanent disability. US doppler and MRI angiography are good tools in early diagnosis and planning if easily available [8]. Intraarterial thrombolytic therapy with urokinase may help in early cases presenting with acute injury [9]. But surgical exploration is necessary if there is suspicion of injury to the artery or haematoma surrounding the major vessel. Such patients require excision of the affected segment with repair by a good vein graft with end-end anastomosis [10-13]. The great saphenous vein is a great option to reconstruct the axillary artery and should be harvested near its femoral junction to get big diameter and thicker wall.

\section{References}

1. Berguer R, Benietz P (1987) Surgical emergencies from intravascular injection of drugs. In: Bergan JJ, Yao JST (Eds.), Vascular Surgical Emergencies. Grune and Stratton, Orlando, USA, pp. 309-318.

2. Maxwell TM, Olcott C, Blaisdell FW (1972) Vascular complications of drug abuse. Arch Surg 105(6): 875-882.

3. Geelhoed GW, Joseph WL (1974) Surgical sequelae of drug abuse. Surg Gynecol Obstet 139(5): 749-755.

4. Williams AW, Montgomery GL (1959) Chemical injury of arteries. J Path Bact 77: 63-69.

5. Ritland D, Butterfield W (1973) Extremity complications of drug abuse. Am J Surg 126(5): 639-648.

6. Goldberg I, Bahar A, Yosipovitch Z (1984) Gangrene of the upper extremity following intra-arterial injection of drugs. Clin Orthop 188: 223-229.

7. Buckspan GS, Franklin JD, Novak GR (1978) Intraarterial drug injury: studies of etiology and potential treatment. J Surg Res 24(4): 294-301.

8. Wilner HI, Kay R, Eisenbrey BA (1974) Pharmacologic aids in angiography of the upper extremity. AJR 121(1): 150-154.

9. Crawford CR, Terranova WA (1990) The role of intra-arterial vasodilators in the treatment of inadvertent intra-arterial injection injuries. Ann Plast Surg 25(4): 279-283.

10. Silverman SH, Turner WW (1991) Intra-arterial drug abuse: new treatment options. J Vasc Surg 14(1): 111-114.

11. Corser G, Masey S, Jacob G (1985) Ischemia following self-administered intra-arterial injection of methylphenidate and diamorphine: a case report of treatment with intra-arterial urokinase and review. Anaesthesia 40(1): 51-55.

12. Daniel DM (1973) The acutely swollen hand in the drug user. Arch Surg 107(4): 548-551.

13. Wright CB, Lamoy RE, Hobson RW (1976) Hemodynamic effects of intra-arterial injection of drugs of abuse. Surgery 79(4): 425-431.
Creative Commons Attribution 4.0 International License

For possible submissions Click Here

\section{Submit Article}

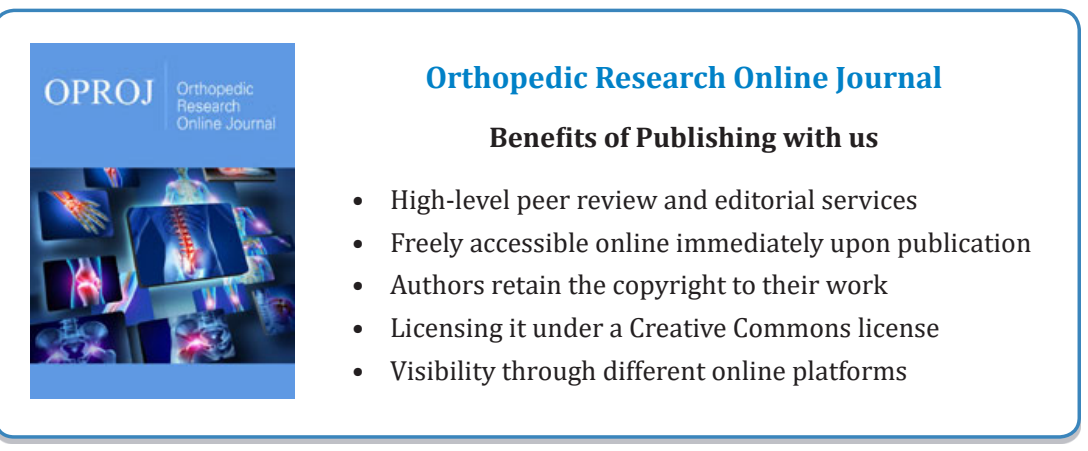

